\title{
On the Evolution of Thermoregulation Models
}

\author{
Palella BI ${ }^{1 *}$, d'Ambrosio Alfano FR $^{2}$ and Riccio G ${ }^{1}$ \\ ${ }^{1}$ Department of Industrial Engineering (DII), University of Naples Federico II, \\ Italy \\ ${ }^{2}$ Department of Industrial Engineering (DIIn), University of Salerno, Italy
}

*Corresponding author: Boris Igor Palella, Dipartimento di Ingegneria

Industriale (DII), Università degli Studi di Napoli Federico II, Piazzale Vincenzo

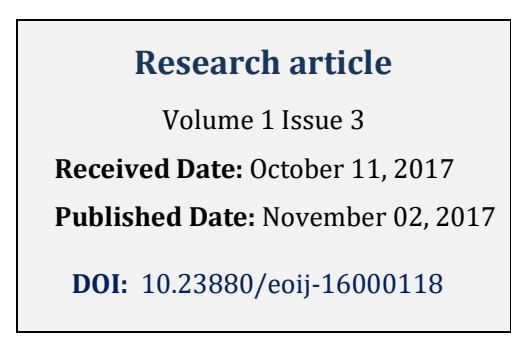

Tecchio 80, 80125, Naples, Italy, Tel: +390817682618; Fax: +39 0812390364; E-mail: palella@unina.it

\section{Abstract}

Thermoregulation models are effective tools for predicting the human response to the thermal environments, assessing thermal comfort and/or thermal stress due to cold or hot conditions, in clothing and automotive research and in building simulation. Fifty years after the first paper by Stolwijk, this work is aimed to the reconstruction of the historical evolution of thermoregulation models based on the bibliography available at the InEQualitES (Indoor Environmental Quality and Energy Saving) team, established in 1983 by professor Gaetano Alfano (University of Naples Federico II) and made by researchers of the DII and DIIn Departments. On the basis of the most recent literature, past and present perspectives of Stolwijk-like models have been also discussed showing the performances of THERMODE 193, a model inspired by the open source philosophy of its precursor and actualized to the recent advances in the field.

Keywords: Thermal Environments; Ergonomics of the Physical Environment; Thermal Comfort; Thermal Stress; Thermoregulation Models; Thermal Response; Physiological Response; Transient Conditions; Non uniform Conditions

\section{Introduction}

As stressed by Hensley et al. [1] and Havenith and Fiala [2], in recent years there has been a growing demand from industry for robust and reliable models predicting human thermophysiological responses. In several applications is required a detailed analysis of the complex environmental heat transfer processes involving human occupancy in order to design safe, comfortable and energy-efficient buildings, in biomedical applications, in cars, or industrial environments in the presence of heat related injuries and also in military and sport [3-10]. This is also proved by the interest of standardization bodies who are preparing special documents aimed to provide basic requirements and general characteristics to design and validate mathematical models for the prediction of the physiological response of a man to the thermal environment.

\section{Methods}

This historical review is aimed to the reconstruction of the evolution of thermoregulation models based on the bibliography available at the InEQualitES (Indoor Environmental Quality and Energy Saving) team, established in 1983 by professor Gaetano Alfano and made by researchers of the DIIn (Department of Industrial Engineering of the University of Salerno) and the DII (Department of Industrial Engineering of the Federico II University in Naples). Based on the most recent literature, the future perspectives of Stolwijk like models have been discussed by showing the performances of a new model inspired by the open 


\section{Ergonomics International Journal}

source philosophy of its precursor and actualized to the recent advances in the field.

\section{Model Features}

A complete thermoregulation model has to be able to schematize two kinds of processes: i) the heat transfer inside the body and between the body and the surrounding environment (passive or controlled system); ii) the mechanisms through which the body controls the thermal exchange to keep its temperature in a restrict field of values (active or controlling system). In literature several classifications of thermoregulation models can be found [11-13]. This paper will show the Hardy's one, which defines two different kind of model: qualitative and quantitative. The former includes verbal, figurative, chemical and neuronal models. The latter is composed by physical and mathematical.

\section{Qualitative Models}

Verbal Models: Verbal models [11] were the first and most rudimentary being quite descriptive and focused on the enunciation of a few hypotheses. Consequently, they have been useful for a rough approach to the problem being not able to describe the complexity of the thermoregulatory system. The first scientist who formulated a verbal model was probably Claude Bernard in 1865 [14] with his "Introduction à l'étude de la médicine éxpérimentale", devoted to the biological regulations.

In 1871 Liebermeister [15] investigated how the thermoregulation is affected by fever saying that "a pyrogenic substance can affect in direct or indirect way the thermoregulation centers in order to set a higher temperature". He also added that "during the febrile illness, the thermoregulation is not lost, but works as in normal conditions". That idea is still valid and it has been partially resumed by the set-point variable theory.

The essential role played by the hypothalamus on the thermoregulation was discussed by Ott and Richet in 1884 [16]. They wrote that "when an animal is exposed to hot or cold environment is able to set its temperature and keep that fixed value" and defined the "thermostatic centers" responsible for the temperature regulation and characterized by thermogenic, thermoinhibitor and thermolytic functions. for the temperature's set-point regulation.

In 1902 Rubner [17] gone beyond Ott's and Richet's model. He introduced three different kinds of temperature regulation (chemical, metabolic and physical) by identifying the range of ambient temperature within the regulation is effective. The important innovation made by Rubner was the application of the first law of thermo-dynamics to the human body.
In 1913 Meyer adopted Ott's idea, in a clearer and more modern way [18] by introducing two different centers with antagonistic functions: a thermogenic center devoted to the energy production in the presence of cold and a thermolytic center responsible for the energy loss in warm environment. Ott-Meyer's model has lasted long to explain thermoregulation.

Figurative Models: These models represent the thermoregulation system in a more complex way than verbal [11]. Unfortunately, it is often simplified as a black box without analyzing the structure and functions of each component. Dubois' model, developed in 1948, is the first figurative model. It contains a large amount of the actual knowledge by describing the neurophysiological components of the thermoregulation system and their connections with effectors, sweat gland, cutaneous bloodstream and skeletal muscles.

In 1952 the Hensel's model connected many physiological functions with two kind of information: inhibition and excitation. Benzinger's, et al. [19] model (Figure 1) recalls Hensel's idea of a central thermal receptor, only sensitive to the warm, while the skin is considered sensitive only to cold sensation. The anterior hypothalamus represents the warm regulation center. It does not receive impulses from other receptors and it converts the temperature signal into nervous impulses returning a vasodilatation or sweating input to the effectors. The regulatory center ofcold translates the signals coming from the skin into a shivering command. Those two centers are interconnected in order to regulate a possible inhibition of the cold regulation considering also the temperature signal of the anterior hypothalamus. This model can be used for a man in activity or not.

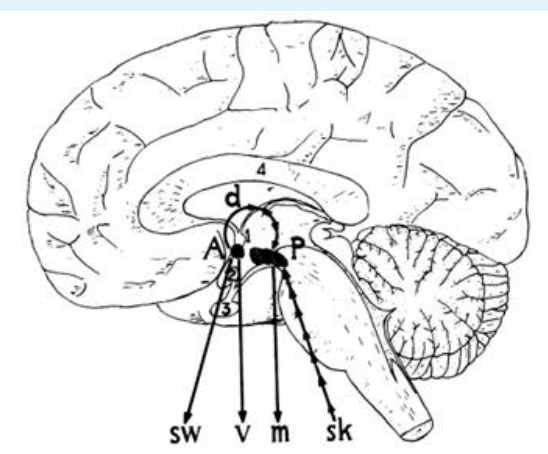

Figure 1: Benzinger and Kitzinger model [19]. (A) Anterior hypothalamus, (P) Posterior hypothalamus, d) internal command pathway, (sw) command pathway of sweat glands, (v) command pathway of skin blood vessels, (m) command pathway of the tissues responsible for thermogenesis, (sk) afferent pathway of information from cutaneous cold receptors, (1) Anterior commissura, (2) Chiasma opticum, (3) Hypophysis, (4) Corpus callosum. 


\section{Ergonomics International Journal}

The model formulated by Chatonnet and Cabanac [20] (Figure 2) starts from the analysis of the anatomical structure. It is the first model accounting a common origin for the physiological and behavioural regulation. The Authors assumed that behavioural regulation is mainly related to the discomfort sensation induced by central and peripheral stimuli and the physiological response.

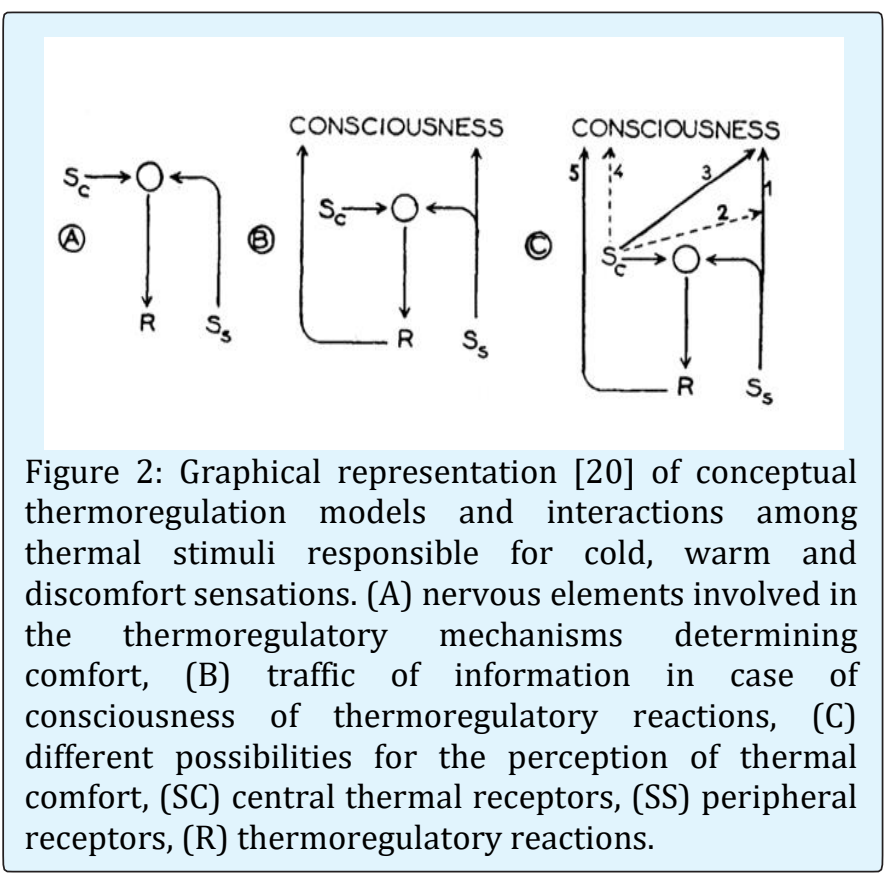

Neuronal Models: From the 60's starts the interest of the scientific community on the role covered by neurons on the thermoregulation system. In these models the thermoregulation is only affected by the nervous system excluding all the other components as hormonal, muscular, vascular, etc. Available models treat only restricted areas of neuronal system involved in the thermoregulation without giving a complete description of it.

The first model based on experimental results was formulated by Hammel in 1965 and reprised in 2006 by Boulant [21]. Most of the components of Hammel's original model are shown in Figure 3. Other simplified models were improved after this, as the Maeskrey and Blight's one [11] which recall the essential features of its precursor: i) the convergence of signals coming from different thermo sensitive areas on complementary neurons; ii) the separation between the neuronal net responsible for the thermolysis from that responsible for the thermogenesis with a mutual effect of inhibition. However, as stressed by Bligh [22], the neural process for explaining the stability of the body temperature of mammals remained almost an open issue. In fact, neither of above discussed hypothesis had been validated unequivocally. Nevertheless, the incorporation of the neurophysiological approach to mathematical thermoregulation models (especially in the case of the skin blood flow control) may be beneficial for research fields, especially in health clinics [23].

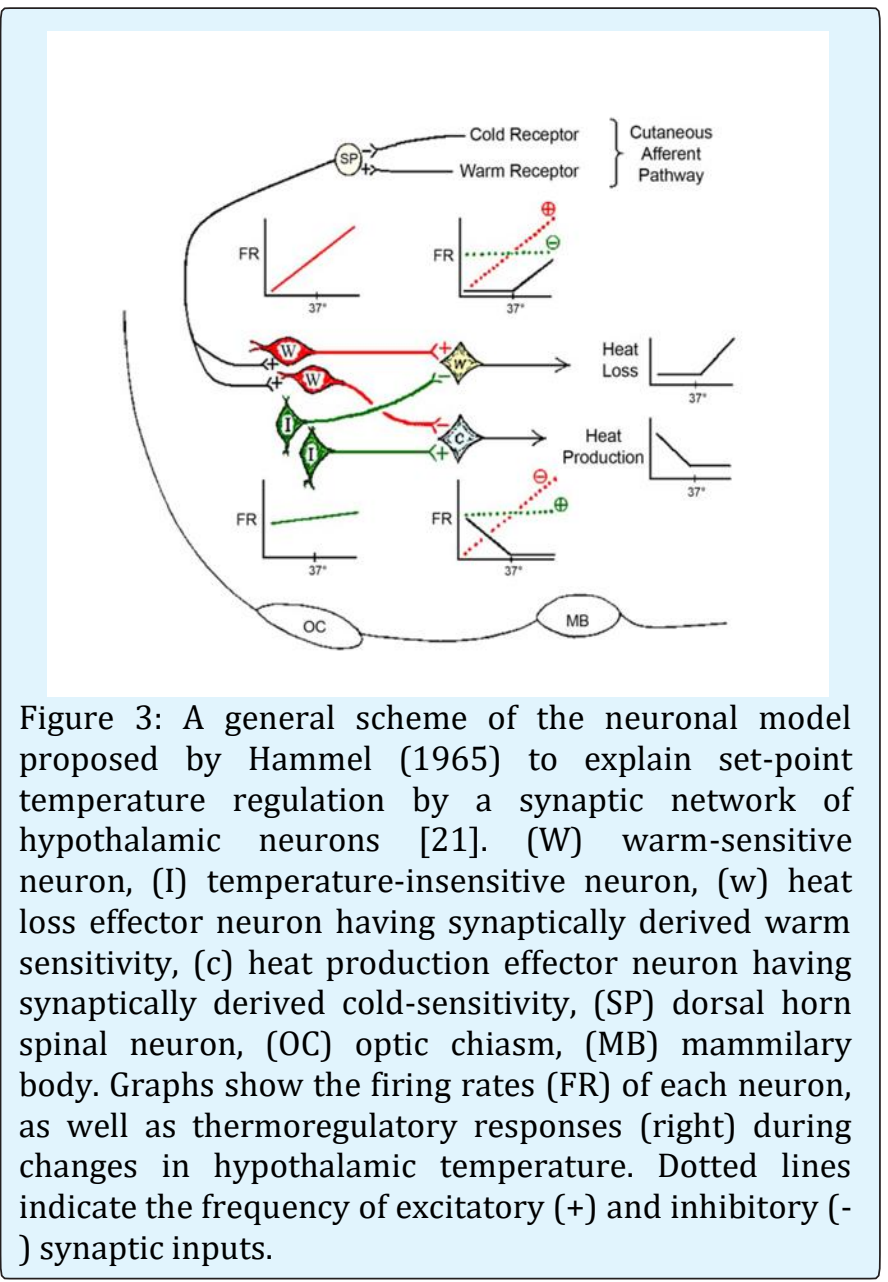

Chemical Models: The interest towards this kind of models started thanks to the studies on the microanatomy of the nervous system carried out by Feldberg and Myers [24]. They injected doses of 5-HT, adrenaline and noradrenaline into the anterior hypothalamus of unanesthetized cats obtaining a hypothermic effect. Models derived from those studies are based on the idea that the transmission or the elaboration of thermoregulatory signals is due to the exchange or the production of chemical substances [11].

\section{Quantitative Models}

Unlike qualitative, these models allow the prediction of several quantities (e.g. core temperature, skin temperature, sweat rate) and numerical simulations [11].

Physical Models: In these models real phenomena are simplified by considering the human body as a black box interacting with the surrounding environment by means of heat flows schematized as indices. Main limits were the incomplete representation of the thermoregulation mechanism, the complexity of 


\section{Ergonomics International Journal}

realization, high costs and low versatility. Nevertheless, they were useful for the comprehension and the study of some particular phenomena.

In 1947, Machle and Hatch [25] built a resistivecapacitive model in which the human body was treated as a heat capacity system and the reactions to the environment as thermal resistances. Metabolic processes were represented as a power unit.

In 1948 Pennes verified the possibility of applying the heat transfer laws to the human body. Based on some tests carried out on the arm of a specific number of subjects, he concluded [26] that Newton's law is useful for estimating the heat transfer between the skin and the environment and Fourier's law for cylindrical symmetry is able to describe conductive heat transfers within the body.

In 1958 Aschoff and Wever [27], taking advantage by the well-known transfer phenomena occurring in heat exchangers, showed the importance of the countercurrent heat exchange in limb.

Another interesting model was formulated by Mac Donald and Wyndham in 1950. They started from the Machle and Hatch's model by adding to it the concept of wet skin, recalled in the '70s as a discomfort index.

Mac Donald and Wyndham's model has been modified and developed during the years, giving rise to Cornew et al.'s one, that considered the human body as made by four layers, for all of which the heat resistance and the heat production are still represented by the electrical analogy. In this model was also considered the evaporative heat flow due to respiration.

\section{Mathematical Models}

The JB Pierce Foundation approached the mathematical modeling of the interaction between the human body and surrounding thermal environment with considerable proficiency already by the 30's [2832].

Based on the differentiation between controlled and controlling system, mathematical models are made by a system of mathematical equations, which describe physical phenomena and/or the hypotheses of the regulation system. The main weakness of this approach was the high level of abstraction balanced by its versatility due to the possibility to modify all parameters, and the hypothesis used. This kind of models was based on the First Law of the Thermodynamics applied to the human body as control volume system. All these models will be discussed on the base of the number of nodes in which human body is partitioned.
One-Cylinder Models: Burton's model [33] was the first mathematical thermoregulation model where the human body is schematized as a homogeneous cylinder and the solution of the heat-balance equations is represented by the Bessel's functions. Burton verified the validity of his model through an experiment in which the subject was put into a bath at $32.5{ }^{\circ} \mathrm{C}$ and quickly heated to $36{ }^{\circ} \mathrm{C}$. He hypothesized that this sudden variation of temperature promoted the vasodilatation so much that the heat conductance was quadruplicated. Burton's experiments also revealed that: i) the temperature stabilization needs a few hours; ii) core temperature firstly decreases, then increases; iii) radial variations of initial and final temperatures are parabolic curves.

In 1966 Stolwijk and Hardy [34] proposed a first model for the evaluation of heat exchange useful for calculating skin and sub-epidermical layers temperature in the presence of radiative sources. This model, which considers the human body divided into 8 layers in series, did not account vasomotion and sweating adjustments. As stressed by Wyndham and Atkins [35] the multi-cylinder Hardy and Stolwijk's model is only a partial solution of the numerical problem of the thermoregulation because did not account existing and complex relation-ships between sweating and conductive heat exchanges, and between the central and peripheral temperatures. They proposed a new model based on Mac Donald and Wyndham's findings [35]. This model was based on two controlling centers. The former affects heat loss mechanisms, by operating on the sweating and the increase of thermal conductance of tissues. The latter is devoted to the energy stored in the body by operating on vasoconstriction and shivering. The centers receive signals from the skin and hypothalamus. Under thermal neutrality or slightly cold conditions, there is no response from the model. For cold exposition, there is a decrease of the inner and surface temperatures. This means that the central and peripheral receptors are excited with the consequent activation of shivering resulting in the increase of both metabolic rate and inner temperature until the attainment of thermal equilibrium. For hot expositions only the dissipation center works being stimulated by the central receptors.

In 1969 Atkins and Wyndham [36] proposed a novel model based on a body partition into four concentric layers:

- Core, made by skeleton and central organs, apart from those related to the blood circulatory system;

- Muscles, responsible for the energy production during exercise;

- Subcutaneous tissues and fat;

- Skin, only scarcely affected by convective heat exchanges with the blood. 


\section{Ergonomics International Journal}

Thermal energy is produced in the muscle and then transferred into the more external layers by convection through the bloodstream and conduction through the tissues. The external layer of the skin is poorly supplied by blood, so in this layer heat transfer occur only by conduction. Each layer of the partition is considered as homogeneous so that the values of heat conductance, heat capacity, metabolic heat production and convective heat transfer rate with blood are uniform.

The conductive heat flow takes place only in radial direction. The blood circulatory system is treated apart: The arterial and the venous blood have the same temperature of the crossed layers, no countercurrent exchange between arterial and venous blood occurs and heat transfer takes place only through the thinner capillaries.

Concerning the controlling system, thermal receptors are placed on the epidermis, marrow and hypothalamus and the inner temperature is considered as the arterial mean one and set point temperatures are used to control the blood flow, the vasomotion, the thermal energy production and the sweating. The model is solved by means of the finite difference method.

The most important one-cylinder model was built by Gagge at the beginning of '70s [37-40], and revisited in 1988 [41,42]. According to Figure 4, human body is modeled as one cylinder with by two concentric and homogeneous layers: the core and the skin on which is placed the clothing-layer.

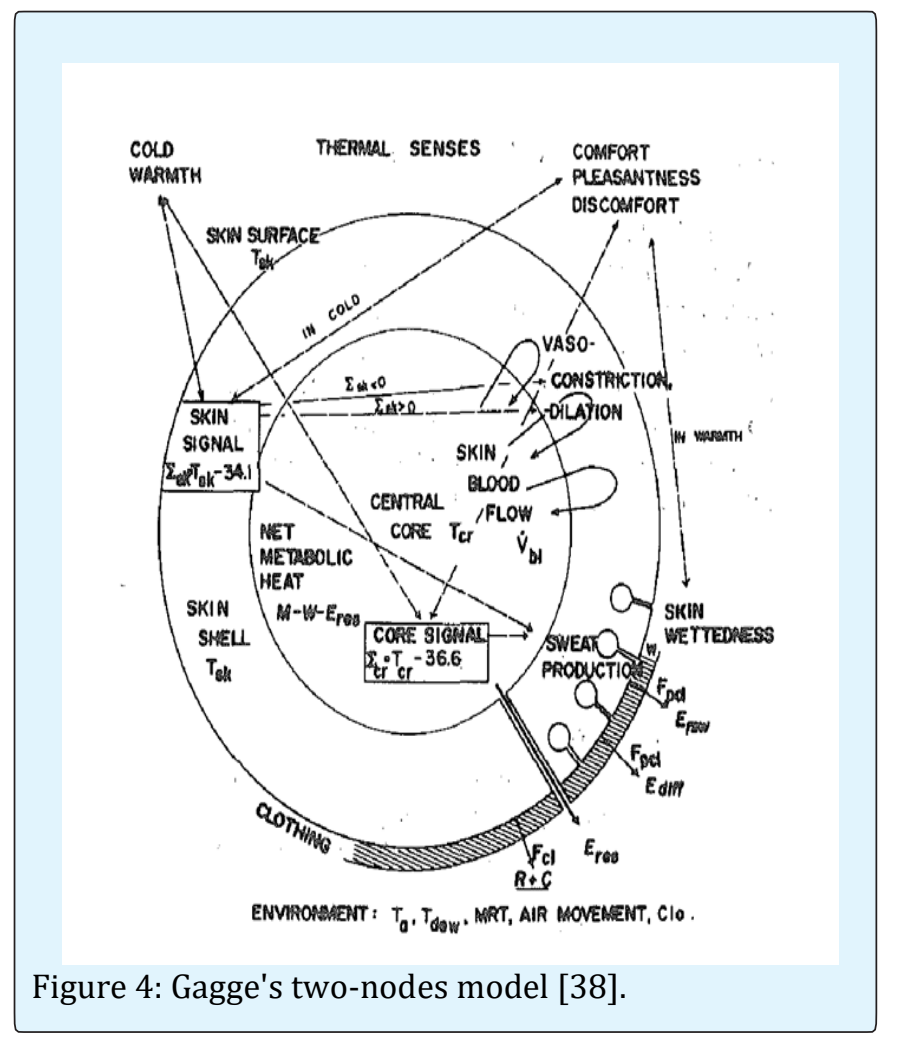

The controlled (passive) system is modeled with heat balance equations for each layer. Heat transfer in the core takes place by: i) convection with the skin due to the blood-vessels convection; ii) conduction with the skin; iii) convection with the surrounding environment due to the breathing (dry and latent contribution). In the core take place the metabolic energy production and the muscle work. The outer layer can exchange energy not only with the nucleus, but also with the environment through evaporation, convection and radiation.

The control (active) system is based on three reference temperatures (core, skin and average) compared with the set point values to produce the error signal. In particular, the signal of warm (cold) from the core is responsible for vasodilatation (vasoconstriction); sweating is linearly proportional to the warm signal coming from the entire body and varies exponentially with the warm signal coming from the skin (for the activation of sweating mechanism both signals are required). Finally, chill depends on cold signals coming from core and skin (chill is activated only if both signals are not zero).

On the Gagge's model (better known as two-nodes model) are based the evaluation of the ET* index (New Effective Temperature) $[43,44]$ proposed by the ASHRAE Standard 55 "Thermal Environmental Conditions for Human Occupancy" and also the SET index (Standard Equivalent Temperature) used in the current version of ASHRAE Standard $55[45,46]$.

The model proposed by Crosbie, et al. [11] schematizes the human body as a three-layers cylinder. The regulated quantity is the mean temperature of body as a function of the core, muscles and skin temperatures. Hardy and Dubois tested this model revealing an acceptable reliability in a wide range of temperatures.

The basic features of Gagge's two-node model are still actual as revealed by some researches published in the last five years $[47,48]$ where new enhanced versions of the early model start to be applied for the prevention of health hazards, for studying comfort conditions during sleep [47] and for developing bio-weather forecasts [48].

Multi-Cylinder Models: In these models the human body is schematized by two or more cylinders, each one consisting in two or more layers. Similarly toonecylinder models, between the different layers there are conductive heat exchanges in radial directions, among the cores of the different layers there are convective heat transfers through the blood flow. Finally the skin surface exchanges heat with the environment by convection, radiation and evaporation. In the core of the 


\section{Ergonomics International Journal}

trunk thermal flows with the surrounding environment are due to the breathing (dry and latent heat loss).

Wissler's Model: In 1961, Wissler [49] proposed a new model, representing the entire thermoregulation system. Wissler found out all the physical and physiological factors that a model has to consider:

- local differences of temperature;

- conductive heat transfers due to differences of temperature;

- convective heat transfers by blood flow;

- body layout;

- thermal conductivity of fat and epidemical layer;

- countercurrent thermal flows between arterial and veins;

- evaporative flow due to breath;

- evaporative flow on the skin;

- heat storage into the body;

- environmental parameters.

In Wissler's model, the human body is a combination of six cylindrical elements (head, trunk arms, hands, legs and feet) and the countercurrent thermal flow between adjacent blood vessels is also considered. Wissler's model has been developed continuously over the past 50 years [50-53] aiming to study new classes of physiological and medical problems [1]. The existing Fortran code was translated in $\mathrm{C}$ with extensive embedded commentary. A graphical user interface has been developed to facilitate convenient user designation of input and output variables and formatting of data presentation. New physiological elements were added to represent the hands and feet, including the unique vascular structures adapted for heat transfer associated with glabrous skin.

Wissler's idea of a more detailed segmentation of the human body achieved resounding success in the following models. One of the first complete models was formulated by Smith and James one in 1964 [54]. They simulated the thermal response of a man exposed to a hot climate. Body consisted of six segments (head, trunk, arms and legs), each one divided into three concentric layers (the core, which contains inner organs, skeleton and muscles, the subcutaneous layer and the skin). The model considers the countercurrent thermal flows in extremities which result a reduction of the heat loss.

Stolwijk's Model: In 1966 Stolwijk and Hardy [34] proposed a new model, schematized in Figure 5, in which the passive system is represented in detail more than previous ones. There are three segments (head, trunk and limbs) each one consisting of three layers (skin, muscles and viscera).

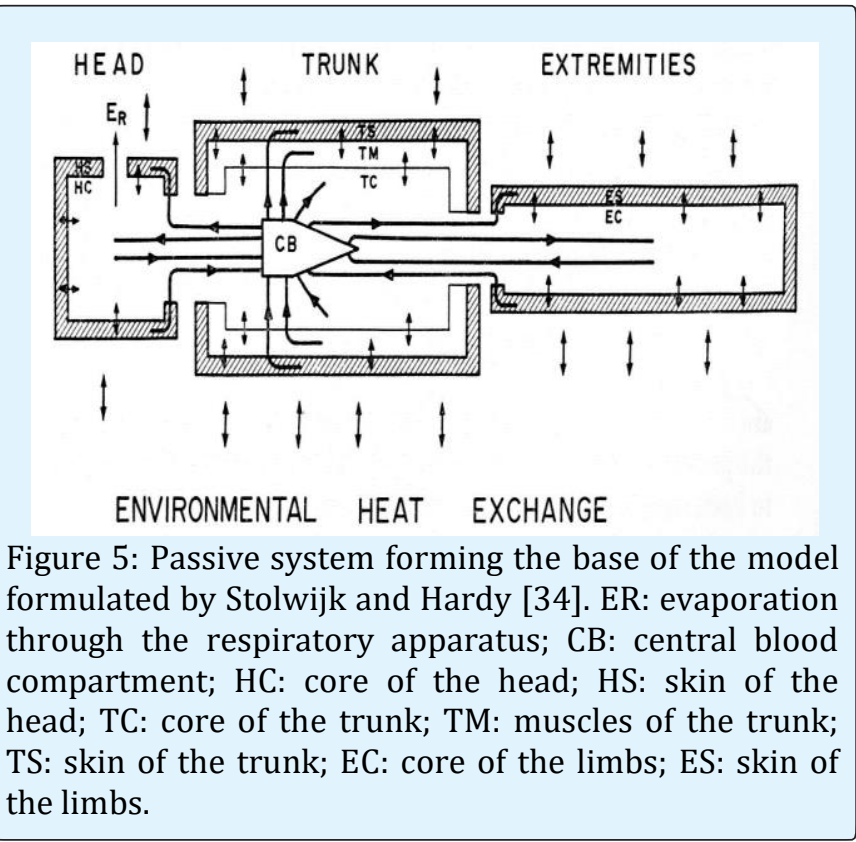

Three temperatures are used for the regulation: the temperature of the central element of the head, representing the hypothalamus, the mean value of the epidermal temperature and the mean temperature of muscles, which is an indicator of the muscular work out. The signal for regulation is proportional to the product between variation of brain and skin temperatures from their set-point. The blood flow in muscles is related only to the metabolic rate (e.g. the activity level of the body). One of the most interesting features of Stolwijk and Hardy's model is the explanation of shivering by means of a self-sustained mechanism. Due to the muscular activity induced by shivering, a significant flow of cold blood reaches the core: this phenomenon results in a reduction of the central temperature which has to be compensated by a further increase of it. Finally, the overproduction of thermal energy causes the shivering interruption, because the temperature will be stabilized on a higher level.

Stolwijk's model [55,56], proposed for the Skylab and Apollo's programs of the NASA and later modified [57], was the first model accounting all the factors underlined by Wissler. Also in this case the passive system consists of six segments: head, trunk, arms, hands, legs and feet. The main peculiarity of the Stolwijk's model is the completeness. In fact, it gives the instantaneous temperature for all the compartments (each segment is made by 4 layers: core, muscle, fat and skin), which could be used for the regulation, and has the maximum flexibility in the data input; furthermore, it resumes in the better way all the thermoregulation knowledge at that time.

Another strength of the model was the implementation of the mathematical model. In particular Stolwijk anticipated the open source logic 


\section{Ergonomics International Journal}

introduced by Stallman in 1985 [58] presently adopted in informatics. This was the reason why Stolwijk provided all equations and coefficients for the model construction and a Fortran code ready to be used and modified by users. Due to above discussed peculiarities, Stolwijk model is still source of inspiration for all researches in this field [59-67] as we will discuss below.

In 1974 Montgomery furnished a different version of the Stolwijk's model focused by focusing the study on the thermal response of a dived man [68]. Gordon's model $[69,70]$ is also interesting: the passive system is an extension of the partition proposed by Wissler: human body consists of 14 segments (forehead, face, cranium, neck, thorax, abdomen, harms, hands, legs and feet), each one with a cylindrical or spherical shape. The deep partition of the head allows to account heat exchanges through the upper respiratory tract in cold severe conditions. The control system is still based on the brain and skin temperature with an additional term related to the thermal flow through the epidermis, evaluated considering the number of thermo receptors per surface unit of each part of the body.

The model was built to simulate the exposition to cold, so it did not consider the sweating but only the evaporative flow due to the vapor diffusion (perspiratio insensibilis). The novelty of the model was the presence of a vasomotor command also for the appendage's muscle. Finally, experimental runs made by the authors revealed a good reliability.

Another model devoted to the simulation of the thermoregulatory response of a dived man was formulated in the same year by Miller and Seagrave [71]. The passive system consists of 15 cylindric elements (head, thorax, abdomen, nearer, median and distal parts of each extremity). Head, thorax and abdomen are divided into three layers (skin, muscle and core) whereas extremities were modeled as 2-layers cylinders. The only thermoregulatory mechanism considered was the vasomotion; whose command signal is proportional to the differences of the hypothalamic and mean cutaneous temperature from their set-point. Thanks to this model, Miller and Seagrave demonstrated tympanic, esophageal and rectal temperatures are not representative of the blood temperature flow reaching the heart.

\section{Recent Models}

Fiala's Model: The model proposed by Fiala was developed to predict the human thermal responses in cold, cool, neutral, warm and hot environments (indoor and outdoor) and was discussed in a two-parts study. The first part is about the passive system [72] in which is shown the model of the human body, heat transfer mechanisms within the body and its periphery and the numerical procedure. The second part [73] analyzes the active system which simulates the regulatory responses of shivering, sweating and peripheral vasomotion of subjects through a regression analysis. Due to a validation in a wide range of experimental conditions (e.g environmental temperature and metabolic rates values in the ranges $5-50^{\circ} \mathrm{C}$ and $0.8-10$ met, respectively) and its excellent performances a special version of it has been used for the formulation of the UTCI (Universal Thermal Climate Index) index [74].

Fiala's model considers the human body covered by a uniform clothing layer and re-simulates the overall insulation characteristics of garments undertaken by McCollough et al. [75,76]. The human body is divided into fifteen spherical or cylindrical elements (head, face, neck, thorax, abdomen, shoulders, arms, hands, legs and feet) divided into seven different layers (brain, lung, bone, muscle, viscera, fat and skin) in accordance with changes of body tissue properties (Figure 6).

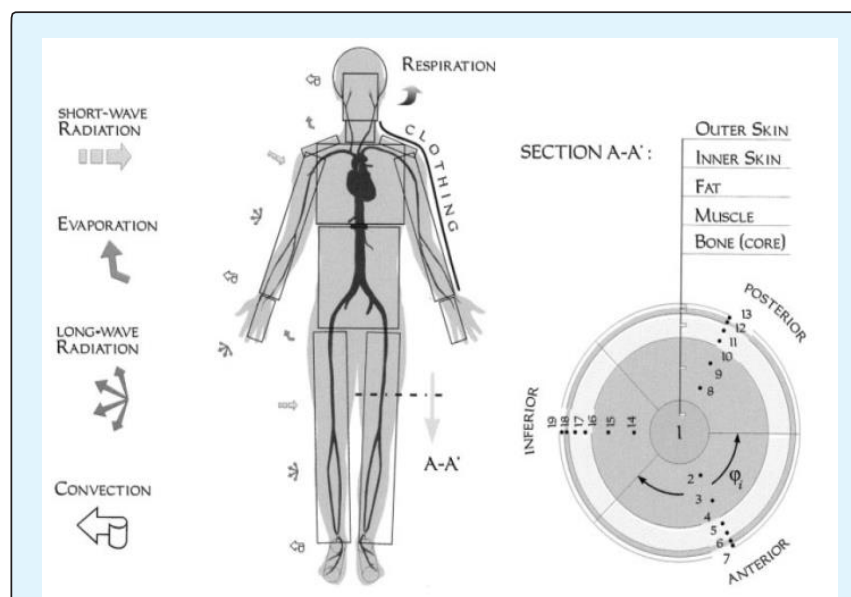

Figure 6: Scheme of the passive component of Fiala's model [72].

According to Weinbaum's et al. findings [77], skin is divided into two layers $1 \mathrm{~mm}$ in thickness with different physiological properties. The inner skin is the region in which the heat is generated and blood is perfused, while the outer skin contains sweat glands and simulates the evaporative barrier for moisture diffusion through the skin. To consider the asymmetric removal of bodily heat, each body elements, except the face and shoulders, is subdivided spatially into sectors: anterior and posterior, that permit the treatment of lateral environmental asymmetries; inferior segments which, considered hidden by other body part, permit to reduce radiant exchange with the environment. The so modelled cylinder also has a core which is defined to have the same radius of the body element's bone.

Despite Stolwijk's model in which heat flow by radiation is evaluated by means of a local heat transfer coefficient, Fiala's model considers both short and long wave radiation. The approach is based upon the concept of directional mean surface temperatures of the enclosure around a single body sector using the 


\section{Ergonomics International Journal}

corresponding view factor. The view factors of the curved body sector surfaces with respect to the enclosure 'seen' are based on numerical radiation simulations using detailed 3D human geometry models [78].

One of the most interesting peculiarities of the Fiala's FPC-model concerns the active system. Unlike Stolwijk's approach $[55,56]$ where effector commands considered for sweating, vasodilatation, vasoconstriction and shivering are obtained by linear addition of central and peripheral afferent signals errors, Fiala's FPC model is based upon non-linear relationships validated experimentally [73].

Fiala's model is worldwide accepted as the reference tool for the prediction of the thermoregulatory response of a man. This is the reason why in a very recent review, it has been extensively tested and compared with a wide database of measurement carried out by 13 different research groups under 43 different expositions (e.g. walking in the cold or in the hot, cycling in moderate and warm environments, wearing protective clothing) both stationary and transient [79]. This investigation revealed good precision in predicting core and mean skin temperatures with a root mean square deviation (RMSD) of 0.26 and $0.92{ }^{\circ} \mathrm{C}$, respectively. Unfortunately, there is a general trend of over-prediction of the forehead head (RMSD $=1.63{ }^{\circ} \mathrm{C}$ ) and thigh skin temperatures (RMSD $\left.=1.41{ }^{\circ} \mathrm{C}\right)$ during exercising exposures. This phenomenon is probably due to the impossibility of the model to account an evaporation efficiency less than $100 \%$. However, as stressed by the authors, one of the most difficulties in the validation of thermoregulation models is that the reliability of experimental data is often affected by the accuracy of measurement techniques as thermocouples or infrared thermography, sensors placement and a general lack of information about the local clothing parameters. Unlike Stolwijk's open source philosophy, the mathematical model of the human thermophysiology by Fiala [72,73] is implemented in a commercially available software [78].

Tanabe's Model: Based on earlier studies by Ozeki et al. [60] the $65 \mathrm{MN}$ model proposed by Tanabe et al. was developed in 2002 [60] and reprised in 2013 to account also heat transfer occurring between veins and arteries [67].

It exhibits four main differences with respect to its precursor which will be quickly discussed:

- A different partition of the human body;

- The presence of clothing;

- The integration with CFD numerical experiments;

- Some modifications in the active system.
The model is based on a partition of 64 elements (the 65th is the blood). The whole body is divided into 16 body segments (head, chest, back, pelvis, left shoulder, right shoulder, left arm, right arm, left hand, right hand, left thigh, right thigh, left leg, right leg, left foot and right foot) each one made by four layers.

To obtain a realistic modeling of heat transfer phenomena occurring on the skin surface (especially in un-homogeneous environments as cars or in the presence of solar radiation), the $65 \mathrm{MN}$ model is also coupled with a radiation exchange model base on a fine mesh of 1542 elements and CFD.

As far the active system is concerned, the structure of equations and coefficients are similar to those reported in the original Stolwijk paper. The only difference to be stressed is that in Tanabe's model the shiver command is only related to the errors coming from the hypothalamus and peripheral receptors.

A more refined version of this model has been developed in the recent past to take into account arterial and venous circulation [67] as in Figure 7. In particular, the blood vessel comprises a central blood compartment, an artery blood pool, a vein blood pool, a surface vein blood pool, and arteriovenous anastomoses (AVA) that connect arteries and superficial veins without exchanging heat with any tissues. For each vessel, the artery and vein blood pools are placed at the center of the core layer in all segments, the superficial veins are placed at the middle of the skin layer in the limbs, and AVA are located in each segment of the hands and feet [80]. During the heat flow calculation stage, the blood flow from the previous segment is assumed to be completely mixed. Because the bloodstream in limb segments varies with the thermal environment, this model simulates physiological phenomena by changing the openness percentage of the AVA to control the blood flow to the surface vein blood pool.

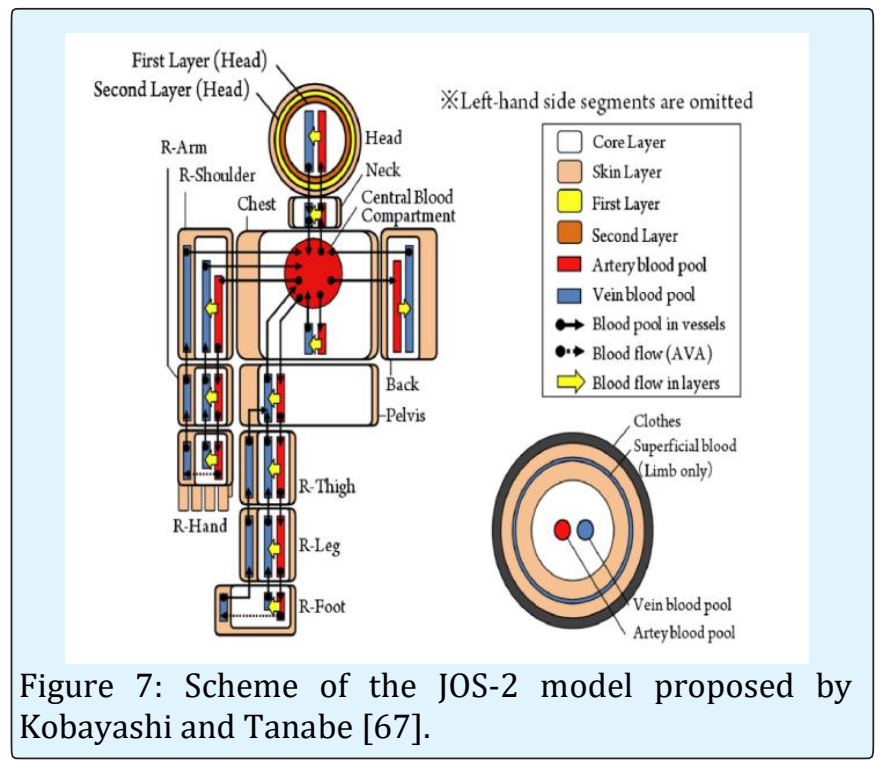




\section{Ergonomics International Journal}

\section{Thermode 193}

The THERMODE (THERmoregulation Model for Disuniform Environments) was developed in the early 90 s as a part of a collaboration between the research team on the Ergonomics of the Thermal Environment of the University of Naples Federico II (Italy) led by Professor Gaetano Alfano and the Laboratoire de Psychologie et Physiologie Environmentales of the French CNRS of Strasbourg [59].

THERMODE model [81] is a Stolwijk-like model developed to account spatial variations around the subject of all microclimatic parameters responsible for the physiological response to the thermal environment (e.g. vertical gradients of air temperature, plane radiant temperature asymmetries, draughts, and unacceptable temperatures of the floor). In addition, it was one of the first models developed for a clothed subject. Its first version was characterized by 129 nodes and exhibited very good performances under comfort and slightly warm conditions except for hands and feet whose temperatures deviated from experimental values up to $2.5^{\circ} \mathrm{C}$ [82]. Aiming to enhance its performances and improve its flexibility, the model has been widely modified consistently with the findings of the last fifteen years.

Despite the first version of THERMODE [63], the passive system is now made by 14 blocks (head, trunk, arms, forearms, hands, legs, ankles and feet).

Each block is divided into several segments as follows:

- head: (upper and lower) each made by four segments (right front, right rear, left front, left rear) for overall 8 segments;

- trunk, arms, forearms, legs, ankles: each made by 4 segments (according to previously reported for the head) for overall 36 segments. This special segmentation allows the treatment of both stand up and seated position.

- hands and feet, each made by one part for overall 4 segments.

Finally, each segment is made by four layers (skin, fat, muscles, core), for an overall number of $48 \times 4=192$ nodes to which blood has to be added, according to figure 8 .

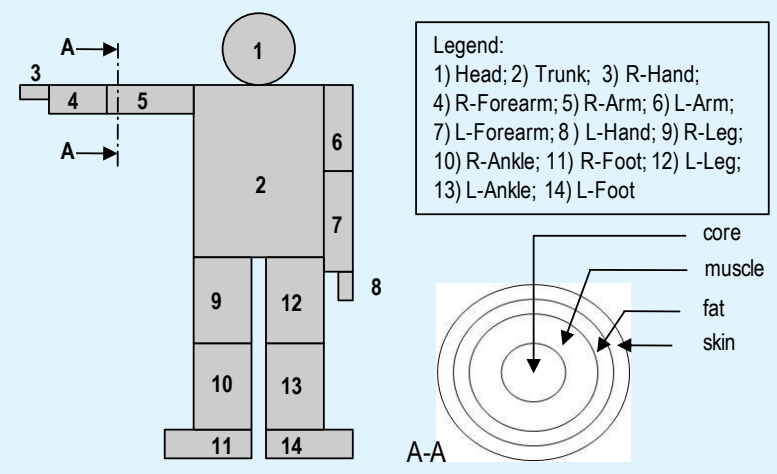

Figure 8: The human body segmentation of THERMODE 193 model [63]

The model can evaluate the clothing thermal insulation of each dressed body part starting from an overall clothing insulation value corrected by the effect of body movements [83-86]. The possibility of using different clothing insulation values for each compartment allows the thermal response evaluation in the presence of protective clothing. The evaluation of the mean radiant temperature of each compartment has been carried out according to ISO 7726 Standard procedures $[87,88]$.

According to Stolwijk's formulation [55,56], controller equations have a term consisting of the product of a control coefficient and a central temperature signal, a term consisting of the product of a control coefficient and an integrated skin temperature signal, and, finally, a third term consisting of the product of a control coefficient, a central temperature signal, and a skin temperature signal according to following equations. All coefficients have been recalculated by means of a special optimization algorithm [82].

The validation of THERMODE 193 is based upon experimental measurements carried out in a special climatic chamber at LPPE by exposing 12 adult subjects (with three different clothing insulation values) to environmental homogeneous conditions consistent with a thermal sensation varying between slightly cold and slightly warm. This means that, according to Fanger's approach [89,90], microclimatic conditions are consistent with a PMV range $[-1 ;+1]$. The overall number of experiments was 108 [59]. 


\section{Ergonomics International Journal}

Data in Table 1 demonstrate a general acceptability of the skin temperature values predicted by THERMODE 193 for each body segment especially under comfort $(\mathrm{PMV}=0)$ and slightly warm $(\mathrm{PMV}=+1)$ conditions with very low deviations with respect to measured values. The only segments affected by less encouraging performances are hands and feet whose deviations exceed $2.5^{\circ} \mathrm{C}$ under cold conditions and low clothing insulation values. This is mainly due to the impossibility of Stolwijk-like models as THERMODE to account counter-current heat exchanges between arterial and venous pool [67] which are very significant in distal segments of the body [91]. However, it is very important to highlight that $\Delta T$ values for this segments are of the same magnitude of the standard deviations of experimental measurements [54] and that they can be improved by operating on the active system with a fitting aimed to find active system coefficients well calibrated on the experimental data [82].

\begin{tabular}{|c|c|c|c|c|c|c|c|}
\hline $\begin{array}{c}\text { I } \\
\text { Icl } \\
\text { clo) }\end{array}$ & PMV & Head & Trunk & Arm & Hand & Leg & Foot \\
\hline \multirow{3}{*}{0.10} & -1 & +0.2 & +1.1 & +1.4 & +2.6 & -0.4 & +1.2 \\
\cline { 2 - 8 } & 0 & 0.0 & +0.9 & +0.5 & +0.8 & -0.5 & +0.6 \\
\cline { 2 - 8 } & +1 & -0.3 & +0.5 & +0.1 & +1.4 & -1.1 & +0.5 \\
\hline \multirow{3}{*}{0.60} & -1 & +0.1 & +0.2 & +0.3 & +2.1 & +0.8 & +1.1 \\
\cline { 2 - 8 } & 0 & +0.5 & +0.5 & +0.5 & +1.9 & +0.3 & +0.8 \\
\cline { 2 - 8 } & +1 & -0.2 & +0.1 & -0.2 & +1.4 & -0.1 & +1.1 \\
\cline { 2 - 8 } \\
\cline { 2 - 8 } & -1 & 0.0 & -0.8 & +0.3 & +1.0 & +1.6 & +1.5 \\
\cline { 2 - 8 } & 0.0 & 0.0 & -0.5 & -0.4 & +0.3 & +1.0 & +0.5 \\
\hline
\end{tabular}

Table 1: Steady state temperature differences, $\Delta \mathrm{T}\left({ }^{\circ} \mathrm{C}\right)$, between experimental local skin temperatures and those predicted by THERMODE 193 for different clothing insulation ( $\left.\mathrm{I}_{\mathrm{cl}}\right)$ and PMV (Predicted mean vote) values.

\section{Conclusion}

Fifty years after Stolwijk's researches addressed to the Apollo-Skylab program, several thermophysiological models for the assessment of human exposures to the thermal environment have been developed. Thanks to the ongoing research in that field, they are today able to predict with acceptable accuracy levels the human response to the thermal environment. Therefore, their application will be more and more extended in all situations where the ergonomic approach is necessary both at analysis and design stages.

\section{Acknowledgement}

A special thanks to Mrs. Alessandra Ranesi (M.Sci in Architecture and Building Engineering) for her precious assistance in the preparation of the first draft of this manuscript. A significant part of this research was developed within the project SMART-CASE Soluzioni innovative multifunzionali per l'ottimizzazione dei consumi di energia primaria e della vivibilità indoor nel sistema edilizio PON 2007-2013 Ricerca e Competitività financed by The Italian Ministry of Education, Universities and Research.

\section{References}

1. Hensley DW, Mark AE, Abella JR, Netscher GM, Wissler EH, et al. (2013) 50 Years of Computer Simulation of the Human Thermoregulatory
System. Journal of Biomechanical Engineering 135(2): 021006.

2. Havenith G, Fiala D (2016) Thermal Indices and Thermophysiological Modeling for Heat Stress. Compr Physiol 6(1): 255-302.

3. de Dear RJ, Akimoto T, Arens EA, Brager G, Candido $C$, et al. (2013) Progress in thermal comfort research over the last twenty year. Indoor Air 23(6): 442-461.

4. Lakhssassi A, Kengne E, Semmaoui H (2010) Modifed Pennes' equation modelling bio-heat transfer in living tissues: analytical and numerical analysis. Natural Science 2(12): 1375-1385.

5. Mezrhab A, Bouzidi M (2006) Computation of thermal comfort inside a passenger car compartment. Appl Therm Eng 26(14): 1697-1704.

6. Havenith G (2001) Individualized model of human for the simulation of heat stress. J Appl Physiol 90(5): 1943-1954.

7. Malchaire JB, Piette A, Kampmann B, Menhert P, Gebhardt HJ, et al. (2001) Development and validation of the predicted heat strain model. Ann Occup Hyg 45(2): 123-135.

8. Yokota M, Berglund LG, Xu X (2014) Thermoregulatory modeling use and application in the military workforce. Appl Ergon 45(3): 663-670. 


\section{Ergonomics International Journal}

9. Van Beek JHGM, Supandi F, Gavai AK, De Graaf AA, Binsl TW, et al. (2011)Simulating the physiology of athletes during endurance sports events: modelling human energy conversion and metabolism. Philos Trans A Math Phys Eng Sci 369(1954): 4295-4315.

10. Formenti D, Ludwig N, Gargano $M$, Gondola $M$, Dellerma N, et al. (2013) Thermal imaging of exercise-associated skin temperature changes in trained and untrained female subjects. Ann Biomed Eng 41(4): 863-871.

11. Hardy JD (1972) Models of temperature regulationA review. In: Essays on temperature regulation, Bligh and Moore (Eds.), North Holland Publishing Company, Amsterdam pp: 163-186.

12. Lotens WA (1988) Comparison of thermal predictive models for clothed humans. ASHRAE Trans 94(1): 1321-1341.

13. Houdas Y (1981) Modelling of heat transfer in man. In: Bioengineering, thermal physiology and comfort, Cena and Clark (Eds.), Elsevier Scientific Publishing Company, Amsterdam 10: 111-121.

14. Bernard C (1966) Introduction à l'étude de la médicine expérimentale, Éditions GarnierFlammarion, Paris pp: 381.

15. Liebermeister C (1871) Uber Warmeregulierung und Fieber. Volkmann's Samml Klein Vortr.

16. DiCara L (1974) Limbic and autonomic nervous system research (Chapter 2), Plenum Press, New York, pp: 428.

17. Rubner M (1902) In: Die Gesetse des Energie Verbrauchs beier Erudhrung. Deutsche, Leipzig.

18. Ingram DL, Mount LE (1975) Man and Animals in Hot environments (chapter 8). Springer, New York pp: 185.

19. Benzinger TH, Pratt AW, Kitzinger C (1961) The thermostatic control of human metabolic heat production. Proc Natl Acad Sci USA 47(5): 730-739.

20. Chatonnec J, Cabanac M (1965) The perception of thermal comfort. Int J Biometereol 9(2): 183-193.

21. Boulant JA (2006) Neuronal basis of Hammel's model for set-point thermoregulation. J Appl Physiol 100(4): 1347-1354.

22. Bligh J (2006) A theoretical consideration of the means whereby the mammalian core temperature is defended at a null zone. J Appl Physiol 100(4): 1332-1337.
23. Kingma BRM, Vosselman MJ, Frijns AJH, van Steenhoven AA, van Marken Lichtenbelt WD (2014) Incorporating neurophysiological concepts in mathematical thermoregulation models. Int J Biometeorol 58(1): 87-99.

24. Feldberg, Myers RD (1965) Changes in temperature produced by micro-injections of amines into the anterior hypothalamus of cats. J Physiol 177(2): 239-245.

25. Mc Donald DKC, Wyndham CH (1950) Heat transfer in man. J Appl Physiol 3: 342-364.

26. Pennes HH (1948) Analysis of tissue and arterial blood temperatures in the resting human forearm. J Appl Physiol 1(2): 93-122.

27. Aschoff J, Wever R (1958) Kern und Schale im Wärmehaushalt des Menschen. Die Naturwissenschaften 45(20): 477-485.

28. Gagge AP (1937) A new physiological variable associated with sensible and insensible perspiration. Am J Physiol 120: 277-287.

29. Gagge AP, Herrington LP, Winslow CEA (1937) Thermal exchanges between the human body and its atmospheric environment. Am J Hyg 26(1): 84102.

30. Gagge AP, Winslow CEA, Herrington LP (1938) The influence of clothing on physiological reactions of the human body to varying environmental temperatures. Am J Physiol 124(1): 30-50.

31. Winslow CEA, Herrington LP, Gagge AP (1936) A new method of partitional calorimetry. Am J Appl Physiol 116: 641-655.

32. Winslow JD, Herrington LP, Gagge AP (1937) Physiological reactions of the human body to varying environmental temperatures. Am J Appl Physiol 120(1): 1-22.

33. Burton AC (1941) The operating characteristics of the human thermoregulatory mechanism. In: Temperature its measurement and Control in Science and Industry, Reinholds Publishing Corporation, New York pp: 522-528.

34. Stolwijk JAJ, Hardy JD (1966) Temperature regulation in man - A theoretical study. Pflugers Arch Gesamte Physiol Menschen Tiere 291(2): 129162 .

35. Windham $\mathrm{CH}$, Atkins AR (1968) A physiological scheme and mathematical model of temperature regulation in man. Pflugers Arch 303(1): 14-30. 


\section{Ergonomics International Journal}

36. Atkins AR, Windham CH (1969) A study of temperature regulation in the human body with the aid of an analogue computer. Pflugers Arch 307(2): 104-119.

37. Nishi Y, Gagge AP (1971) Humid operative temperature. A biophysical index of thermal sensation and discomfort. J Physiol-Paris 63(3): 365-368.

38. Gagge AP, Stolwijk JAJ, Nishi Y (1971) An effective temperature scale based on a simple model of human physiological regulatory response. Ashrae Trans 77(1): 247-262.

39. Gagge AP (1973) A two node model of human temperature regulation in FORTRAN. In:

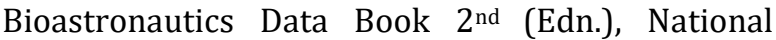
Aeronautics and Space Administration, Washington D.C.: $142-148$.

40. Gagge AP (1973) Rational temperature indices of man's thermal environment and their use with a 2node model of his temperature regulation. Federation Proc 32(5): 1572-1582.

41. Gagge AP, Fobelets AP, Berglund LG (1986) A Standard Predictive Index of Human Response to the Thermal Environment. ASHRAE Trans 92(2B): 709-731.

42. Fobelets APR, Gagge AP (1988) Rationalization of the effective temperature, ET*, as a measure of the enthalpy of the human indoor environment. ASHRAE Trans 94(1): 12-31.

43. Alfano G, d'Ambrosio FR, Riccio G (1997) La valutazione delle condizioni termoigrometriche negli ambienti di lavoro: comfort e sicurezza. Napoli, Italy Cuen srl.

44. ASHRAE (2017) Thermal comfort (Chapter 9). In: ASHRAE Fundamentals. American Society of Heating Refrigerating and Air Conditioning, Atlanta.

45. Fountain ME, Huizenga C (1997) A thermal Sensation Prediction Tool for Use by Profession. ASHRAE Trans 103(2): 130-136.

46. ASHRAE (2013) Thermal environmental conditions for human occupancy. In: ANSI/ASHRAE Standard 55, American Society of Heating, Refrigerating and Air Conditioning Engineers, Atlanta.

47. Dongmei P, Mingyin C, Shiming D, Minglu Q (2012) A four-node thermoregulation model for predicting the thermal physiological responses of a sleeping person. Build Environ 52: 88-97.
48. Kurazumi Y, Sakoi T, Tsuchikawa T, Fukagawa $\mathrm{K}$ Dimitrov Bolashikov Z, et al. (2014) Behavioral Thermoregulation Model for Evaluation of Outdoor Thermal Environment. Journal of Ergonomics 4(1): 1-14.

49. Wissler EH (1961) Steady-state temperature distribution in man. J Appl Physiol 16(4): 734-740.

50. Wissler EH (1963) An analysis of factors affecting temperature levels in the nude human. In: Temperature its measurements and control in science and industry. Reinholds Publishing Corporation, New York pp: 603-612.

51. Wissler EH (1966) A mathematical model of the human thermal system. Chem Eng Prog SympSer 62: 66-79.

52. Wissler EH (1970) The use of finite difference techniques in simulating the human thermal system. In: Hardy, et al. (Eds.), Physiological and behavioural temperature regulation pp: 367-388.

53. Wissler EH (1971) Comparison of computed results obtained from two mathematical models: a simple 14-node model and a complex 250-node model. J Physiol-Paris 63: 455-458.

54. Smith PE, James EW (1964) Human responses to heat stress. Arch Environ Health 9(3): 332-342.

55. Stolwijk JAJ (1970) Mathematical model of thermoregulation. In: Hardy, et al. (Eds.), Physiological and behavioural temperature regulation pp: 730-721.

56. Stolwijk JAJ (1971) A Mathematical Model of Physiological Temperature Regulation in Man. NASA CR 1855 Report. National Aeronautics and Space Administration, Washington DC, USA.

57. Stolwijk JAJ, Nadel ER, Wenger CB, Roberts MF (1973) Development and application of a mathematical model of human thermoregulation. Arch Sci Physiol 27(3): 303-310.

58. http://www.gnu.org/gnu/about-gnu.html

59. Candas V, d'Ambrosio FR, Herrmann C (1993) A mathematical model of thermoregulation to evaluate thermal comfort. Proceedings of 2nd International Conference on Energy and Environment towards the year 2000, Capri, Italy 2: 1031-104.

60. Tanabe S, Kobayashi K, Nakano J, Ozeki Y, Konishi M (2002) Evaluation of thermal comfort using combined multi-node thermoregulation (65MN) 


\section{Ergonomics International Journal}

and radiation models and computational fluid dynamics (CFD). Energ Buildings 34(6): 637-646.

61. van Marken Lichtenbelt WD, Frijns AJH, Fiala D, Janssen FEM, van Ooijen AMJ, et al. (2004) Effect of individual characteristics on a mathematical model of human thermoregulation. J Therm Biol 29(7): 577-581.

62. van Marken Lichtenbelt WD, Frijns AJH, van Ooijen MJ, Fiala D, Kester AM, et al. (2007) Validation of an individualized model of human thermoregulation for predicting responses to cold air. Int J Biometeorol 51(3): 169-179.

63. d'Ambrosio Alfano FR, Palella BI, Riccio G (2008) Thermode 193: an enhanced Stolwijk thermoregulation model of the human body. Proceedings of 7th international thermal manikin and modelling meeting, University of Coimbra, Portugal pp 1-8.

64. Sukstanskii AL, Yablonskiy DA (2004) An analytical model of temperature regulation in human head. J Therm Biol 29(7): 583-587.

65. Yi L, Aihua M, Ruomei W, Xiaonan L, Zhong W, et al. (2006) P-smart-a virtual system for clothing thermal functional design. Comput Aided Design 38(7): 726-739.

66. Munir A, Takada S, Matsushita T (2009) Reevaluation of Stolwijk's 25-node human thermal model under thermal-transient conditions: Prediction of skin temperature in low-activity conditions. Build Environ 44(9): 1777-1787.

67. Kobayashi Y, Tanabe S (2013) Development of JOS2 human thermoregulation model with detailed vascular system. Building Environ 66: 1-10.

68. Montgomery LD (1974) A model of heat transfer in immersed man. Ann Biomed Eng 2(1): 19-46.

69. Gordon RG, Roemer RB (1975) The effect of radial modal spacing on the performance of a mathematical model of the human temperature regulatory system. IEEE T- Biomed Eng 22(1): 8083.

70. Gordon RG, Boemer RB, Horvath SM (1976) A mathematical model of the human temperature regulatory system: transient cold exposure response. IEEE T-Biomed Eng 23(6): 434-444.

71. Miller NC, Seagrave RC (1974) A model of human thermoregulation during water immersion. Comput Biol Med 4(2): 165-182.
72. Fiala D, Lomas KJ, Stohrer M (1999) A computer model of human thermoregulation for a wide range of environmental conditions: the passive system. J Appl Physiol 87(5): 1957-1972.

73. Fiala D, Lomas K, Stohrer M (2001) Computer prediction of human thermoregulatory and temperature responses to a wide range of environmental conditions. Int J Biometeorol 45(3): 143-159.

74. Fiala D, Havenith G, Bröde P, Kampmann B, Jendritzky G (2012) UTCI-Fiala multi-node model of human heat transfer and temperature regulation. Int J Biometeorol 56(3): 429-441.

75. McCullough EA, Jones BW, Huck J (1985) A comprehensive data base for estimating clothing insulation. ASHRAE Trans 92: 29-47.

76. McCullough EA, Jones BW, Tamura T (1989) A data base for determining the evaporative resistance of clothing. ASHRAE Trans 95: 316-328.

77. Weinbaum S, Jiji LM, Lemons ED (1984) Theory and experiment for the effect of vascular microstructure on surface tissue heat transfer. Part I: anatomical foundation and model conceptualization. J Biomech Eng 106(4): 321-330.

78. Fiala D, Psikuta A, Jendritzky G, Paulke S, Nelson DA, et al. (2010) Physiological modeling for technical, clinical and research applications. Frontiers in Bioscience - Scholar 2(S3): 939-968.

79. Martínez N, Psikuta A, Kuklane K, Quesada JI, de Anda RM, et al. (2016) Validation of the thermophysiological model by Fiala for prediction of local skin temperatures. Int J Biometeorol 60(12): 1969-1982.

80. Takemori T, Nakajima K, Shoji Y (2005) The development of thermoregulatory model. J Jpn Soc Mech Eng 61: 1513-1520.

81. Lenzi P, Libert JP, Franzini C, Cianci T, Guidalotti PL (1986) Short-term thermoregulatory adjustments involving opposite temperature changes. J Term Biol 11(3): 151-156.

82. Lopardo G, Palella BI (2010) Ottimizzazione del Sistema attivo di un modello avanzato di termoregolazione corporea. $65^{\circ}$ Congresso Nazionale ATI. Domus de Maria (Italy).

83. Havenith G, Nilsson H (2004) Correction of clothing insulation for movement and wind effects, a metaanalysis. Eur J Appl Physiol 92(6): 636-640. 
84. d'Ambrosio Alfano FR, Palella BI, Riccio G, Malchaire J (2016) On the Effect of Thermophysical Properties of Clothing on the Heat Strain Predicted by PHS Model. Ann Occup Hyg 60(2): 231-251.

85. Wang F, del Ferraro S, Lin L, Sotto Mayor T, Molinaro V, Ribeiro M, Gao C, Kuklane K, Holmér I (2012) Localized boundary air layer and clothing evaporative resistances for individual body segments. Ergonomics 55(7): 799-812.

86. Lu Y, Wang F, Wan X, Song G, Zhang C, et al. (2015) Clothing resultant thermal insulation determined on a movable thermal manikin. Part II: effects of wind and body movement on local insulation. Int J Biometeorol 59(10): 1487-1498.

87. ISO (1998) Ergonomics of the thermal environment - instruments for measuring physical quantities ISO Standard 7726. International Standardization Organization, Geneva.
88. d'Ambrosio Alfano FR, Dell'Isola M, Palella BI, Riccio G, Russi A (2013) On the measurement of the mean radiant temperature and its influence on the indoor thermal environment assessment. Build Environ 63: 79-88.

89. Fanger PO (1970) Thermal Comfort, Danish Technical Press, Copenhagen.

90. d'Ambrosio Alfano FR, Olesen BW, Palella BI (2017) Povl Ole Fanger's impact ten years later. Energ Buildings 152: 243-249.

91. Shephard JT (1983) Circulation to skeletal muscle. In: Shepherd JT, Abboud FM (Eds.), Handbook of physiology. Section 2: The cardiovascular system. Volume III: Peripheral circulation and organ blood flow. American Physiological Society, Bethesda, Maryland pp: 319-370. 